\title{
Phlebotomine sandfly fauna and natural Leishmania infection rates in a rural area of Cerrado (tropical savannah) in Nova Mutum, State of Mato Grosso in Brazil
}

\author{
Sirlei Franck Thies ${ }^{[1]}$, Ana Lucia Maria Ribeiro ${ }^{[2]}$, Érika Monteiro Michalsky ${ }^{[3]}$, \\ Rosina Djunko Miyazaki ${ }^{[4]}$, Consuelo Latorre Fortes-Dias ${ }^{[5]}$, Cor Jésus Fernandes Fontes ${ }^{[6]}$ \\ and Edelberto Santos Dias ${ }^{[3]}$
}

[1]. Curso de Pós Graduação em Ciências da Saúde, Faculdade de Medicina, Universidade Federal de Mato Grosso, Cuiabá, MT. [2]. Faculdade de Medicina, Universidade Federal de Mato Grosso, Cuiabá, MT. [3]. Laboratório de Leishmanioses, Centro de Pesquisas René Rachou, Belo Horizonte, MG. [4]. Departamento de Biologia e Zoologia, Instituto de Biociências, Universidade Federal de Mato Grosso, Cuiabá, MT. [5]. Diretoria de Pesquisa e Desenvolvimento, Fundação Ezequiel Dias, Belo Horizonte, MG. [6]. Departamento de Clínica Médica, Faculdade de Medicina, Universidade Federal de Mato Grosso, Cuiabá, MT.

\begin{abstract}
Introduction: American cutaneous leishmaniasis (ACL) has been reported in every municipality of the State of Mato Grosso, Brazil, but the transmission epidemiology remains poorly understood. Our study was developed in a rural area of the Nova Mutum municipality where four autochthonous cases of ACL were reported in 2009. Our aims were to describe the local phlebotomine sandfly fauna and to investigate the infection rates and infecting Leishmania species in the captured sandflies. Methods: Entomological captures were performed bimonthly at 10 fixed sites close to the edge of a forested area between June 2011 and April 2012. Results: A total of 3,743 phlebotomine sandflies belonging to 31 distinct species were captured. Approximately $75 \%$ of the specimens were females. The most abundant species (45.4\%) was Lutzomyia antunesi, which was consistently captured at every site. Species that are epidemiologically important for ACL, such as L. flaviscutellata, L. whitmani and L. umbratilis, were also captured. L. antunesi and L. ubiquitalis were naturally infected by Leishmania braziliensis or Le. guyanensis, with minimum infection rates of $0.88 \%$ and $6.67 \%$, respectively. Surprisingly, L. antunesi was infected by Le. infantum (synonym chagasi). Conclusions: The natural infection of $L$. antunesi and L. ubiquitalis by Leishmania sp. suggests that these species might play a role in the zoonotic cycle of ACL in Nova Mutum. The presence of Le. infantum in L. antunesi suggests that there may be a risk of an outbreak of visceral leishmaniasis (VL) in Nova Mutum.
\end{abstract}

Keywords: Phlebotomine sandfly. Leishmania. American cutaneous leishmaniasis. Nova Mutum. Lutzomyia.

\section{INTRODUCTION}

Leishmaniases are among the most prevalent infectious diseases caused by parasites in the world and display a wide distribution in the Americas, Africa, India, Asia and Mediterranean Europe ${ }^{1,2}$. Leishmaniases occur in approximately 90 different countries, currently infecting 14 million people with an increase of 2 million new cases per year. It is estimated that 350 million people are at risk for these diseases ${ }^{2}$, which are caused by protozoa that belong to the Leishmania genus. Transmission occurs through the bite from infected phlebotomine sandflies (Diptera, Psychodidae). Several mammal species may act as natural reservoirs or hosts for

\footnotetext{
Address to: Dr. Edelberto Santos Dias. Laboratório de Leishmanioses/CPqRR. Av. Augusto de Lima 1715, 30190-002 Belo Horizonte, MG, Brasil.

Phone: 5531 3349-7758.

e-mail: edel@cpqrr.fiocruz.br

Received 10 February 2013

Accepted 24 May 2013
}

leishmaniases. Humans and some domestic animals, including dogs and horses, are considered to be accidental hosts ${ }^{3}$.

Human cases of American cutaneous leishmaniasis (ACL) have been reported in every Brazilian State ${ }^{4}$. In Mato Grosso (MT), ACL is endemic with 8,000 reported cases between 2009 and 2011 (MS/SINAN/SES/MT, 2011). Since 2005, autochthonous cases of ACL have been reported from every municipality of the state ${ }^{5}$.

Lutzomyia whitmani, a phlebotomine sandfly species that is widely distributed in Brazil, is the main species associated with ACL transmission in $\mathrm{MT}^{4}$. This fly can be found in various MT biomes, such as Cerrado (tropical savannah), the Amazonian rainforest and Pantanal (tropical wetland). The phlebotomine sandfly fauna in these biomes is widely diversified and consists of species such as Lutzomyia flaviscutellata, L. intermedia, L. migonei, L. umbratilis, L. wellcomei and L. whitmani $i^{5,6}$ all of them involved in the transmission epidemiology of ACL.

The identification of potential vector species for ACL and the natural rate of Leishmania infection are of fundamental importance for understanding the medical entomology and epidemiology of ACL, particularly in endemic regions. Applying molecular biology techniques, such as the polymerase chain 
reaction (PCR), enables the identification of genetic material of Leishmania in the total DNA extracted from phlebotomine sandfly macerates, even in minimal amounts. The main advantages of PCR are its sensitivity and specificity, regardless of the number, location or stage of the infecting Leishmania in the digestive tract of the sandfly? ${ }^{7}$. In the last decade, PCR has been widely used in studies of vector competence of phlebotomine sandflies, even in areas with low rates of Leishmania infection ${ }^{8-11}$. Although MT is considered endemic for ACL, natural infection investigations on $A C L$ vectors are rare there. Only three studies on natural infection by Leishmania have been reported in the state, two of which are related to visceral leishmaniasis (VL) vectors ${ }^{12,13}$, and a third investigated a single $L$. umbratilis specimen that was infected by Le. braziliensis ${ }^{14}$.

The goal of present study was to survey the phlebotomine sandfly in a rural area of the State of Mato Grosso in qualitative and quantitative terms, as well as to determine the natural rate of Leishmania sp. infection in the phlebotomine sandfly females captured there. The area under study is located in the municipality of Nova Mutum, where four autochthonous ACL cases were reported in 2009.

\section{METHODS}

\section{Area under study}

Nova Mutum $\left(13^{\circ} 05^{\prime} 04^{\prime \prime} \mathrm{S}, 56^{\circ} 05^{\prime} 16^{\prime \prime} \mathrm{W}\right)$ is a $9,572.69 \mathrm{~km}^{2}$ municipality that is located in the mid-Northern area of the Brazilian State of Mato Grosso (Figure 1). Our study was developed in a rural area of Cerrado (tropical savannah) that has an area of 16,000 hectares, and is located at $42 \mathrm{~km}$ from the city center of Nova Mutum. The location has a native forest that consists of small to large trees (Figure 2) and has an ample amount of decaying vegetal organic matter. Various animal species can be found there, including monkeys, wild pigs, snakes, rats, scouts and armadillos. The area attracts people who engage in activities that put them in close contact with nature, such as swimming and fishing.

\section{Phlebotomine sandfly capture and identification}

Six entomological captures were performed bimonthly for three consecutive nights between June 2011 and April 2012. Ten Center for Disease Control (CDC) light traps were set five feet from the ground and $100 \mathrm{~m}$ from one another at a transect of approximately 1,000 meters between the edge and the interior of the forest. The capture sites were plotted by GPS. The captured phlebotomine sandflies were packed in insulated containers and taken to the laboratory for adequate assembling and identification, as described by Young and Duncan ${ }^{15}$. The specimens were incorporated into the collection of the Entomology laboratory from the Health Department of Mato Grosso. The phlebotomine female sandflies were identified by dissecting the last three segments to allow for the visualization of the abdominal spermathecae and by head dissection to allow for the examination of specific taxonomic characteristics. Damaged specimens were identified at the genus level only. One to 10 specimens of phlebotomine female sandflies were pooled according to species, date and site of capture, and were then stored in $6 \%$ dimethyl sulfoxide (DMSO) at $-20^{\circ} \mathrm{C}$ until use.

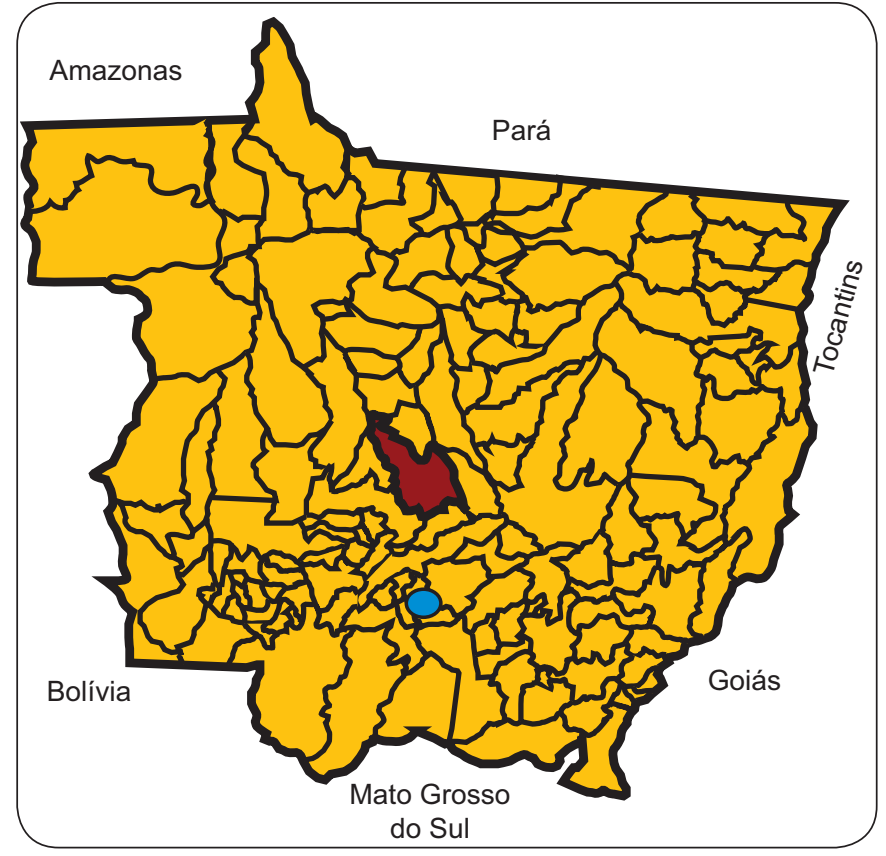

FIGURE 1 - Geographical localization of the municipality of Nova Mutum (in red) in the State of Mato Grosso, Brazil. The capital of Mato Grosso, Cuiabá, is indicated by a solid blue circle.

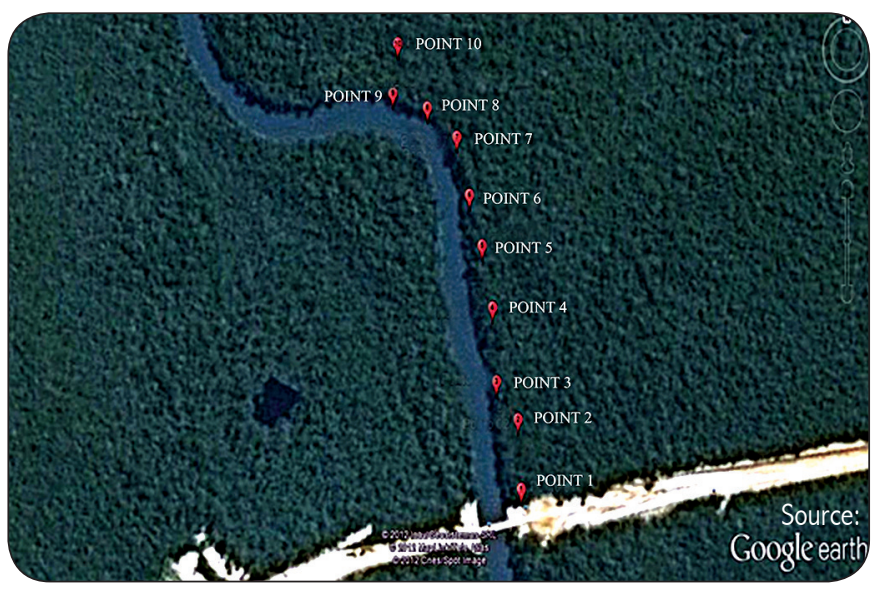

FIGURE 2 - Aerial view of the area under study in Nova Mutum, State of Mato Grosso, Brasil. The sites of entomological captures are indicated by red balloons.

\section{Lutzomyia constitutive gene (cacophony)}

The adequacy of DNA extraction from the phlebotomine sandflies was checked by polymerase chain reaction (PCR) with specific primers to the IVS6 region of the Lutzomyia genus (cacophony), as described by Lins ${ }^{16}$.

\section{Detection of Leishmania DNA in phlebotomine sandflies}

Pooled samples of phlebotomine female sandflies were submitted to total DNA extraction using a commercial kit (GE HealthCare, Uppsala, Sweden). The presence of Leishmania DNA was tested by nested PCR (LnPCR) with primers that were directed at the small subunit ribosomal ribonucleic acid (SSUrRNA) gene ${ }^{17,18}$. The first amplification step was performed using R221 and R332 primers that are specific to the Kinetoplastida order but not exclusively to the Leishmania genus. 
The PCR products were then tested using a new amplification step with R233 and R333 primers $^{18}$. All amplifications were performed with the Illustra PuRe Taq Ready-To-Go PCR Beads kit (GE Healthcare, Uppsala, Sweden), and the products were analyzed using electrophoresis in agarose gels. DNA from Le. braziliensis (M2903 strain) and sterile distilled water were used as the positive and negative controls, respectively.

\section{Identification of the Leishmania species in phlebotomine sandflies}

The amplified bands from the PCR steps were extracted from the gels using the QIAquick extraction kit (QIAGEN, Hilden, Germany) and submitted for DNA sequencing using an ABI3130 analyzer (Applied Biosystems Inc., Foster City, California, USA). The sequences were analyzed using the Blast Nucleotide Standard software (blast.ncbi.nlm.nih.gov).

\section{Minimum rates of Leishmania infection in phlebotomine sandflies}

The minimum rates of Leishmania infection in the captured phlebotomine sandflies were calculated by dividing the number of positive pools of each sandfly species by the number of specimens of that species in that pool and then multiplying by $100^{19}$.

\section{RESULTS}

A total of 3,743 phlebotomine sandfly specimens were captured in Nova Mutum. Of the captured specimens, 1,008 $(26.9 \%)$ were males $(\mathrm{M})$ and $2,735(73.1 \%)$ were females $(\mathrm{F})$, which resulted in an overall $\mathrm{M} / \mathrm{F}$ ratio of $0.4 \%$ (Table 1 ). The phlebotomine sandfly fauna consisted of 31 different species. The predominant species was Lutzomyia antunesi (Coutinho, 1939), which accounted for approximately $45 \%$ of the total captured specimens. L. flaviscutellata (Mangabeira, 1942), L. whitmani (Antunes \& Coutinho, 1939) and L. umbratilis (Ward \& Fraiha, 1977), all known ACL vectors, were also captured at the following percentages: $6.49 \%, 0.19 \%$ and $0.03 \%$, respectively (Table 1).

A total of 2,419 sandflies females were dissected and pooled for molecular analysis. Then, 293 pooled samples were obtained, which were distributed by species as follows: 196 of L. antunesi, 71 of L. flaviscutellata, eight of L. yuilli yuilli, 16 of L. ubiquitalis, one of L. umbratilis and one of $L$. whitmani. After LnPCR, the 353bp DNA fragment of the Leishmania genus was observed in 13 of the pooled samples ( 11 from $L$. antunesi and two from L. ubiquitalis [Figure 3]). No amplification products were detected in the remaining samples. The minimum rates of Leishmania infection were $0.88 \%$ and $6.67 \%$ for L. ubiquitalis and $L$. antunesi, respectively. The adequacy of the Lutzomyia DNA extraction was confirmed by the amplification of the cacophony gene in all 13 positive Leishmania samples (data not shown).

After the DNA sequencing and nucleotide alignment of the 353bp amplicons from the Leishmania-containing phlebotomine samples (Figure 3), the infecting Leishmania species were identified as follows: Le. braziliensis (GQ332355)
TABLE 1 - Phlebotomine sandfly species captured with CDC light traps in a rural area of Nova Mutum, State of Mato Grosso, Brazil. Period: June 2011 to April 2012.

\begin{tabular}{|c|c|c|c|c|c|c|}
\hline \multirow[b]{2}{*}{ Species } & \multicolumn{2}{|r|}{ Female } & \multicolumn{2}{|r|}{ Male } & \multicolumn{2}{|c|}{ Total } \\
\hline & $\mathrm{n}$ & $\%$ & $\mathrm{n}$ & $\%$ & $\mathrm{n}$ & $\%$ \\
\hline B. brumpti & 14 & 0.51 & 6 & 0.60 & 20 & 0.53 \\
\hline L. antunesi & 1,265 & 46.25 & 436 & 43.26 & 1,701 & 45.45 \\
\hline L. aragaoi & 4 & 0.15 & - & - & 4 & 0.11 \\
\hline L. ayrozai & 33 & 1.21 & - & - & 33 & 0.88 \\
\hline L. begonae & 28 & 1.02 & - & - & 28 & 0.75 \\
\hline L. bourrouli & 6 & 0.22 & 1 & 0.10 & 7 & 0.19 \\
\hline L. chagasi & 15 & 0.55 & - & - & 15 & 0.40 \\
\hline L. claustrei & 14 & 0.51 & 20 & 1.98 & 34 & 0.91 \\
\hline L. complexa & 1 & 0.04 & 4 & 0.40 & 5 & 0.13 \\
\hline L. dasypodogeton & 12 & 0.44 & 6 & 0.60 & 18 & 0.48 \\
\hline L. davisi & 3 & 0.11 & 2 & 0.20 & 5 & 0.13 \\
\hline L. flaviscutellata & 146 & 5.34 & 97 & 9.62 & 243 & 6.49 \\
\hline L. furcata & 37 & 1.35 & 1 & 0.10 & 38 & 1.02 \\
\hline L. hermanlenti & 9 & 0.33 & 9 & 0.89 & 18 & 0.48 \\
\hline L. lenti & 1 & 0.04 & - & - & 1 & 0.03 \\
\hline L. llanosmartinsi & 46 & 1.68 & 2 & 0.20 & 48 & 1.28 \\
\hline L. longipennis & 9 & 0.33 & 6 & 0.60 & 15 & 0.40 \\
\hline L. octavioi & - & - & 5 & 0.50 & 5 & 0.13 \\
\hline L. punctigeniculata & 2 & 0.07 & - & - & 2 & 0.05 \\
\hline L. runoides & 2 & 0.07 & 2 & 0.20 & 4 & 0.11 \\
\hline L. sallesi & - & - & 3 & 0.30 & 3 & 0.08 \\
\hline L. saulensis & 677 & 24.75 & 93 & 9.23 & 770 & 20.57 \\
\hline L. shannoni & 34 & 1.24 & - & - & 34 & 0.91 \\
\hline L. shawi & 1 & 0.04 & - & - & 1 & 0.03 \\
\hline L. sordellii & 16 & 0.58 & 3 & 0.30 & 19 & 0.51 \\
\hline L. spp. & 16 & 0.58 & 9 & 0.89 & 25 & 0.67 \\
\hline L. ubiquitalis & 43 & 1.57 & 83 & 8.23 & 126 & 3.37 \\
\hline L. umbratilis & 1 & 0.04 & - & - & 1 & 0.03 \\
\hline L. walkeri & 282 & 10.31 & 212 & 21.03 & 494 & 13.20 \\
\hline L. whitmani & 1 & 0.04 & 6 & 0.60 & 7 & 0.19 \\
\hline L. yuilli yuilli & 17 & 0.62 & 2 & 0.20 & 19 & 0.51 \\
\hline Total & 2,735 & 100.0 & 1,008 & 100.0 & 3,743 & 100.0 \\
\hline
\end{tabular}

B.: Brumptomyia; L.: Lutzomyia; CDC: Center for Disease Control.

or Le. guyanensis (GQ332358) in six pooled L. antunesi samples (numbered 190, 224, 233, 246, 256 and 275) and in two pooled L. ubiquitalis samples (numbered 264 and 265); Le. infantum (GQ 332359) was identified in one pooled sample of $L$. antunesi. Poor DNA sequencing results were obtained for the four remaining samples. 


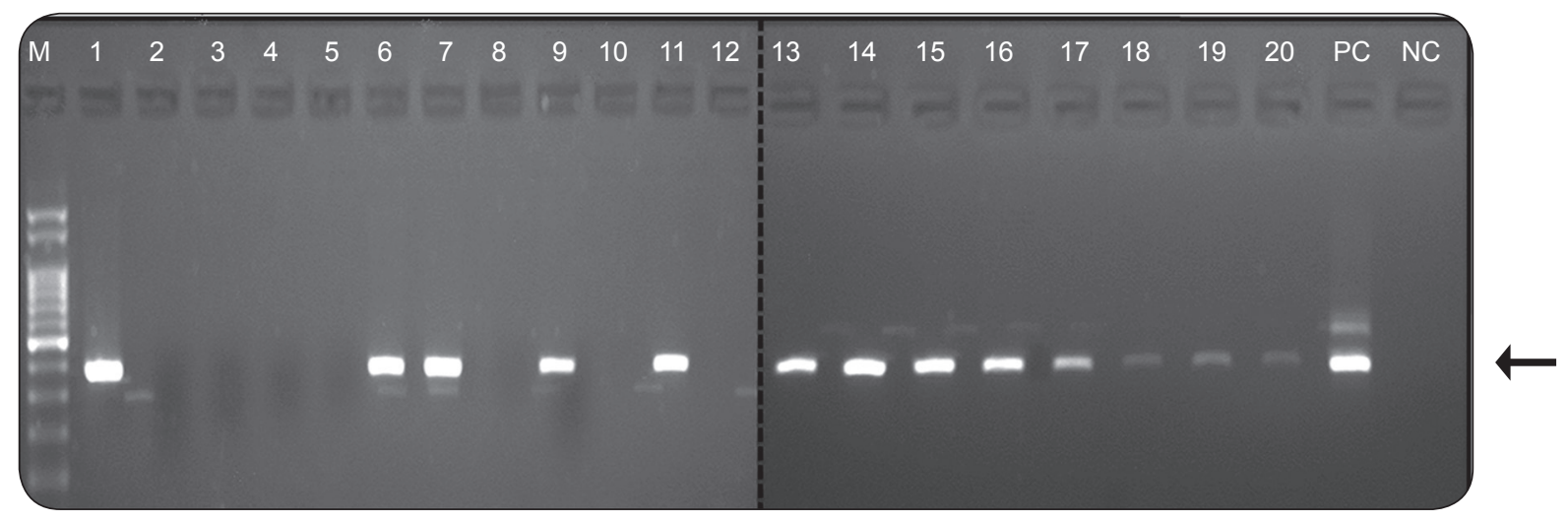

FIGURE 3 - Agarose gel electrophoresis of the LnPCR products after amplifying the total phlebotomine sandfly DNA for the SSUrRNA gene of Leishmania sp. The characteristic 353bp fragment (indicated by an arrow) was present in the following samples: L. umbratilis (18 and 19); L. antunesi (1, 6, 7, 9, 11, 13, 14, 15, 16, 17 and 20). PC: positive control (Le. braziliensis M2903); NC: negative control (no DNA); and M: 100bp DNA ladder.

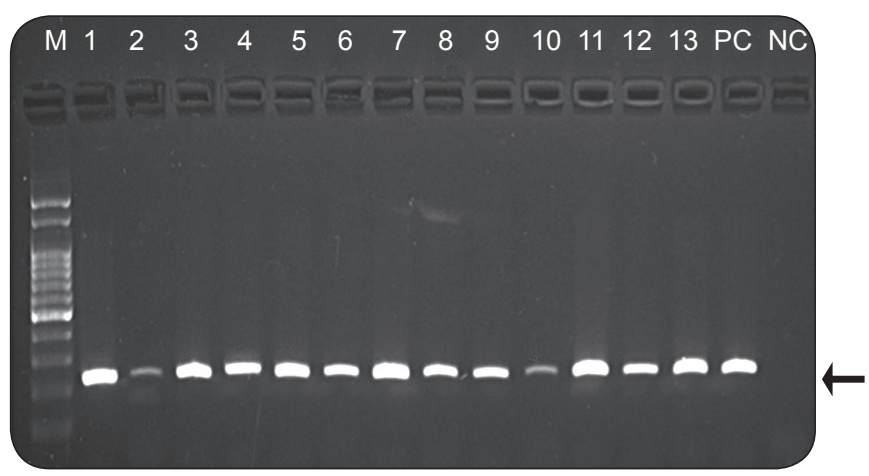

FIGURE 4 - Agarose gel electrophoresis of the PCR products obtained after amplifying the total phlebotomine sandfly DNA with primers for the cacophony IV6 gene of Lutzomyia. The characteristic 220bp fragment is indicated by an arrow. Samples: L. umbratilis (11 and 12); L. antunesi (1 to 10,13); PC: Positive control (L. longipalpis DNA); NC: negative control (no DNA); and M: 100 bp DNA ladder.

\section{DISCUSSION}

The phlebotomine sandfly fauna of the State of Mato Grosso is quite diversified, consisting of more than 100 species whose spatial distribution varies according to the different biomes present $^{21,24}$. In the rural Cerrado (tropical savannah), which was under study, roughly $50 \%$ of the captured specimens were L. antunesi. L. longipalpis and L. cruzi, which are both proven vectors of the visceral leishmaniasis (VL) in Brazil, were not captured at that location. This result differed from the capture reports in urban areas with Cerrado fragments ${ }^{23,25}$. Surprisingly, even in the absence of $L$. longipalpis and $L$. cruzi and no reported cases of VL, Le. infantum was present in a pooled sample of L. antunesi from Nova Mutum. A previous finding of promastigotes in L. antunesi with a VL focus in the Marajó Island (State of Pará) led the authors to suggest that the sandfly species could be involved as a secondary VL vector on that island. The authors also suggested the possibility of Le. infantum infection in $L$. antunesi, although the inoculation of isolated promastigotes from the sandflies produced no skin lesions in hamsters ${ }^{26}$.
Regarding ACL vectors, L. whitmani (vector of Le. braziliensis, Le. guyanensis and Le. shawi), L. flaviscutellata (vector of Le. amazonensis), L. ubiquitalis (vector of Le. lainsoni), L. umbratilis (vector of Le. guyanensis) and $L$. antunesi (epidemiologically shown to transmit $L e$. lindenbergi) were captured in Nova Mutum. L. ubiquitalis has been previously found in forested areas in Brazil, Peru and Bolivia and is the only known vector of Le. lainsoni so far $^{27}$.

Studies on natural Leishmania infection in the State of Mato Grosso are rare, with the exception for two that were published by Missawa ${ }^{12,13}$ regarding proven VL vectors ${ }^{12}$. In Brazil, estimated infection rates of ACL vectors by Leishmania ranged from $0.16 \%$ to $7.1 \%: 0.4 \%$ in Bahia ${ }^{11}$ and Maranhão State ${ }^{28}$, from $0.8 \%$ to $7.1 \%$ in Minas Gerais ${ }^{29}, 2 \%$ in Rio de Janeiro ${ }^{30}, 0.3 \%$ in Porto Alegre ${ }^{31}$, and $0.16 \%$ in Serra dos Carajás, Pará ${ }^{32}$. In Nova Mutum (MT) we found minimum infection rates of $0.8 \%$ for Le. (V.) braziliensis or Le. (V.) guyanensis and $0.08 \%$ for Le. (L.) infantum in $L$. antunesi, For L. ubiquitalis, the minimum rate of infection was $6.67 \%$ for Le. braziliensis or Le. guyanensis. There are no previous reports of Leishmania infection in any of these phlebotomine sandflies species. Vásquez-Trujillo ${ }^{33}$ found L. antunesi naturally infected with Leishmania spp. and suggested its involvement in the transmission cycle of ACL in Colombia.

Genetically speaking, Le. braziliensis and Le. guyanensis are closely related species. We attempted to distinguish them in the Leishmania infected sandflies using hsp $70^{34}$ methodology. However, only one pooled sample of $L$. antunesi showed the expected amplified product (1300bp) (data not shown). After gel extraction, that DNA fragment provided insufficient sequencing results.

In a study conducted at the Reference Center for Leishmaniasis in Cuiabá (MT) using isozyme typing and molecular analysis, most (94.1\%) ACL cases were because of infection by Le. braziliensis, whereas Le. amazonensis was the causative parasite in the others ${ }^{35}$. In another study that investigated patients from MT that were diagnosed with Le. amazonensis, Le. braziliensis and Le. shawi were determined to be the infecting species ${ }^{36}$. Although we were unable to discriminate between Le. braziliensis and Le. guyanensis in our 
infected sandfly samples, it seems probable that the parasite was Le. braziliensis, as opposed of Le. guyanensis.

Based on the occurrence of autochthonous human cases of ACL and on the presence of $L$. antunesi and L. ubiquitalis that are infected by Leishmania (most likely Le. braziliensis), it is possible to hypothesize that those phlebotomine sandfly species might be involved in the zoonotic cycle of ACL in the rural Cerrado of Nova Mutum (MT).

\section{CONFLICT OF INTEREST}

The authors declare that there is no conflict of interest.

\section{FINANCIAL SUPPORT}

Fundação de Amparo à Pesquisa de Mato Grosso (FAPEMAT; process 505189/2009) and of the Health Department of Mato Grosso.

\section{REFERENCES}

1. Medeiros ACR, Rodrigues SS, Roselino AMF. Comparison of the especificity of PCR and histopathological detection of leishmania for the diagnosis of American cutaneous leishmaniasis. Braz J Med Biol Res 2002; 35:421-424.

2. World Health Organization. Control of leishmaniasis. Report of the secretariat. [Cited 2007 September 09] 2006; Available from: http://www. who.int/gb/ebwha/pdf_files/EB118/B118_4-en.pdf.

3. Lainson R, Shaw JJ. Evolution, classification and geographical distribution, In: W. Peters, Killick-Kendrick, editors. The Leishmaniasis in Biology and Medicine. Vol 1 - Biology and Epidemiology. London, UK: Academic Press; 1987. p. 1-20.

4. Ministério da Saúde. Secretaria de Vigilância em Saúde. Departamento de Vigilância Epidemiológica. Atlas de leishmaniose tegumentar americana: diagnósticos clínico e diferencial. Brasília: Editora do Ministério da Saúde; 2006.

5. Missawa NA, Maciel GBML, Rodrigues H. Distribuição de Lutzomyia (Nissomyia) withmani (Antunes e Coutinho, 1939) no estado de Mato Grosso. Rev Soc Bras Med Trop 2008; 41:369-373.

6. Ribeiro ALM, Missawa NA. Spatial distribuition of Phlebotomine species in the state of Mato Grosso, Brazil, in the period of 1996 to 2011. Entomol y Vectores 2002; 9:33-34.

7. Perez JE, Ogusuku E, Inga R, Lopez M, Monje J, Paz L, et al. Natural Leishmania infection of Lutzomyia spp. in Peru. Trans R Soc Trop Med Hyg 1994; 88:1614.

8. Silva AC, Grunewald GMS. Contribuition to the sand fly fauna (Diptera:Phlebotominae) of Rio Grande do Sul, Brazil, and Leishmania (Viannia) infections. Mem Inst Oswaldo Cruz 1999; 94:579-5825.

9. Rodriguez N, Aguilar CM, Barrios MA, Barker DC. Detection of Leishmania braziliensis in naturally infected individual sandflies by the polymerase chain reaction. Trans R Soc Trop Med Hyg 1999; 93:47-49.

10. Aransay AM, Scoulica E, Tselentis Y. Detection and identification of Leishmania DNA within naturally infected sand flies by seminested PCR on minicircle kinetoplastic DNA. Appl Environ Microbiol 2000; 66:1933-1938.

11. Miranda JC, Reis E, Schreifer A, Gonçalves M, Reis MG, Carvalho L, et al Frequency of infection of Lutzomyia phlebotomines with Leishmania braziliensis in a Brazilian endemic area as assessed by pinpoint capture and polymerase chain reaction. Mem Inst Oswaldo Cruz 2002; 97: 185-188.
12. Missawa NA, Michalsky EM, Fortes-Dias CL, Dias ES. Lutzomyia longipalpis naturally infected by Leishmania (L.) chagasi in Várzea Grande, Mato Grosso State, Brazil, an area of intense transmission of visceral leishmaniasis. Cad Saude Publica 2010; 26:2414-2419.

13. Missawa NA, Veloso MAE, Maciel GBML, Michalsky EM, Dias ES. Evidência de transmissão de leishmaniose visceral por Lutzomyia cruzi no município de Jaciara, Estado de Mato Grosso, Brasil. Rev Soc Bras Med Trop 2011; 44:76-78.

14. Pereira TR apud Azevedo ACR, Souza NA, Meneses CRV, Costa WA, Costa SM, Lima JB, et al. Ecology of sand flies (Diptera: Psychodidae: Phlebotominae) in the North of the state of Mato Grosso, Brazil. Mem Inst Oswaldo Cruz 2002; 97:459.

15. Young PG, Duncan MA. Guide to the identification and geographic distribution of Lutzomyia sandflies in México, the West India, Central and South America (Diptera: Psychodidae). Florida: Publishers American Entomological Institute; 1994.

16. Lins RMMA, Oliveira SG, Souza NA, Queiroz RG, Justiniano SCB, Ward RD, et al. Molecular evolution of the cacophony IVS6 region in sand flies. Insect Mol Biol 2002; 11:117-122.

17. Van Eys GJJM, Schoone GJ, Kroon NCM, Ebeling SB. Sequence analysis of small subunit ribosomal RNA genes and its use for detection and identification of Leishmania parasites. Mol Biochem Parasitol 1992; 51:133-142.

18. Cruz I, Canãvate C, Rubio JM, Morales MA, Chicharro C, Laguna F, et al. A nested polymerase chain reaction (Ln-PCR) for diagnosing and monitoring Leishmania infantum infection in co-infected patients with human immunodeficiency virus. Trans R Soc Trop Med Hyg 2002; 96:185-189.

19. Paiva BR, Secundino NFC, Pimenta PFP, Galati E, Andrade Jr HF, Malafronte RS. Padronização de condições para detecção de DNA de Leishmania spp. em flebotomíneos (Diptera, Psychodidae) pela reação em cadeia da polimerase. Rev Parasitol Vet 2007; 23:41-45.

20. Missawa NA, Maciel GB. List of species in the genus Lutzomyia, França, 1924 (Psychodidae, Phlebotominae) from the State of Mato Grosso. Rev Soc Bras Med Trop 2007; 40:11-14.

21. Ribeiro ALM, Missawa NA, Zeilhofer P. Distribution of phlebotomine sandflies (Diptera: Psychodidae) of medical importance in Mato Grosso State, Brazil. Rev Inst Med Trop São Paulo 2007; 49:5.

22. Maciel GBML, Missawa NA. Fauna flebotomínica (Diptera: Psychodidae) em aldeias indígenas do Estado de Mato Grosso. Rev Soc Bras Med Trop 2009; 42:597-602.

23. Amaral AFS, Varjão JR, Silva GB, Arrais-Silva WW. Phlebotomine fauna (Diptera: Psychodidae: Phlebotominae) in a residential area and in a fragment of savanna vegetation in the municipality of Pontal do Araguaia, Mato Grosso, Brazil. Rev Bras Parasitol Vet 2011; 20:165-167.

24. Alves GB, Oshiro ET, Leite MC, Melão AV, Ribeiro LM, Mateus NLF, et al. Phlebotomine sandflies fauna (Diptera: Psychodidae) at rural settlements in the municipality of Cáceres, state of Mato Grosso, Brazil. Rev Soc Bras Med Trop 2012; 45: 437-443.

25. Queiroz MFM, Varjão JR, Moraes SC, Salcedo GE. Analysis of sand flies (Diptera: Psychodidae) in Barra do Garças, State of Mato Grosso, Brazil, and the influence of environmental variables on the vector density of Lutzomyia longipalpis (Lutz \& Neiva, 1912). Rev Soc Bras Med Trop 2012; 45:313-317.

26. Ryan L, Silveira FT, Lainson R, Shaw JJ. Leishmanial infections in Lutzomyia longipalpis and Lu. antunesi (Diptera: Psychodidae) on the island of Marajó, Pará State, Brazil. Transc Roy Soc Trop Med Hyg 1984; 78:547-548

27. Silveira FT, Lainson R, Shaw JJ, Braga RR, Ishikawa EEA, Souza AAA. Cutaneous leishmaniasis in Amazonian: isolation of Leishmania (Viannia) lainsoni from the rodent Agouti paca (Rodentia: Dasyproctidae) in the state of Pará, Brazil. Rev Inst Med Trop São Paulo 1991; 33:18-22.

28. Oliveira-Pereira YN, Rebêlo JMM, Moraes JLP, Pereira SRF. Diagnóstico molecular da taxa de infecção natural de flebotomíneos (Psychodidae, Lutzomyia) por Leishmania sp. na Amazônia maranhense. Rev Soc Bras Med Trop 2006; 39:540-543. 
29. Carvalho GML, Andrade-Filho JD, Falcão AL, Gontijo CMF. Naturally infected Lutzomyia sandflies and the transmission of leishmaniasis in an endemic area of Brazil. Vector Borne Zoonotic Dis 2008; 8:407-414.

30. Pita-Pereira D, Alves CR, Souza MB, Brazil RP, Bertho AL, Barbosa AF, et al. Identification of naturally infected Lutzomyia intermedia and Lutzomyia migonei with Leishmania (Viannia) braziliensis in Rio de Janeiro (Brazil) reveled by PCR multiples non-isotopic hibrydisation assay. Trans R Soc Trop Med Hyg 2005; 99:905-913.

31. Pita-Pereira D, Souza GD, Zwetsch A, Alves CR, Britto C, Rangel EF. First report of Lutzomyia (Nyssomyia) neivai (Diptera: Psychodidae:Phlebotominae) naturally infected by Leishmania (Viannia) braziliensis in a periurban area of south Brazil using a multiplex polymerase chain reaction assay. Am J Trop Med Hyg 2009; 80:593-595.

32. Souza AAA, Silveira FT, Lainson R, Barata IR, Silva MGS, Lima JAN, et al. Fauna flebotomínica da Serra dos Carajás, Estado do Pará, Brasil, e sua possível implicação na transmissão da leishmaniose tegumentar americana. Rev Pan-Amaz Saúde 2010; 1:45-51.
33. Vásquez-Trujillo A, Santamaría-Herreño E, González-Reina AE, BultragoÁlvarez LS, Góngora-Orjuela A, Cabrera-Quintero OL. Lutzomyia antunesi, probable vector de Leishmaniasis Cutánea em el área Rural de Villavicencio. Rev Salud Publica 2008; 10:625-632.

34. Garcia L, Kindt A, Bermudez H, Llanos-Cuentas A, Doncker S, Arevalo J, et al. Culture-independent species typing of neotropical Leishmania for clinical validation of a PCR-based assay targeting heat shock protein 70 genes. J Clin Microbiol 2004; 42:2294-2297.

35. Carvalho MLR, Andrade ASR, Fontes CJF, Hueb M, Silva SO, Melo MN. Leishmania (Viannia) braziliensisis the prevalent species infecting patients with tegumentary leishmaniasis from Mato Grosso State, Brazil. Acta Tropica 2006; 98:277-285.

36. Graça GC, Volpini AC, Romero GAS, Oliveira Neto MP, Hueb M, Porrozzil R, et al. Development and validation of PCR-based assays for diagnosis of American cutaneous leishmaniasis and identification of the parasite species. Mem Inst Oswaldo Cruz 2012; 107:664-674. 